TYPING

PRACTICE 


\section{TYPING PRACTICE}

\section{A. H. Gurney,}

A.C.P., P.C.T., A.S.C.T., M.F.T.Com.

Lecturer Responsible for Secretarial Studies,

Hebburn Technical College.

\section{MACMILLAN EDUCATION}


All rights reserved. No part of this publication may be reproduced or transmitted, in any form or by any means, without permission.

First published 1973 by THE MACMILLAN PRESS LTD

London and Basingstoke

Associated companies in New York Toronto

Dublin Melbourne Johannesburg and Madras

SBN 333138465

\section{ISBN 978-0-333-13846-5 ISBN 978-1-349-01607-5 (eBook) DOI 10.1007/978-1-349-01607-5}

Set I.B.M. by

GEORGE OVER LIMITED, LONDON AND RUGBY 


\section{PREFACE}

This book is designed to give extra, graded practice in the various aspects of the Certificate in Secondary Education and the Royal Society of Arts Stage I Typewriting examinations to students who are working under the direction of a teacher. It assumes a knowledge of the keyboard, parts of the machine, and centring.

The exercises are graded to allow students to progress from models or very easy examples by gradual stages up to examination standard.

Teachers will find that the book contains a ready-made supply of appropriate exercises but without any instruction or teaching material as it is the author's intention to leave the teacher entirely free to teach by her own methods. Occasional reminders and hints are given

(a) to help teachers to keep their better students usefully occupied while other students are proceeding at a slower pace, and

(b) to enable a student to use appropriate sections of the book for both revision and practice to remedy particular weaknesses.

I would like to thank the Royal Society of Arts, the Northern Counties Technical Examinations Council, and the EP Group of Companies for permission to use parts of past examination papers and catalogues.

A. H. GURNEY 


\section{CONTENTS}

1. TYPES OF PARAGRAPH

Exercises

Typed and displayed examples of hanging, block and indented paragraphs to be $1-3$

copied and kept for reference

Exercises on the different types of paragraph

$4-7$

2. MANUSCRIPT

Manuscript exercises on A5 paper without headings or correction signs

$8-10$

3

Manuscript exercises on A5 paper with headings but without correction signs

Manuscript exercise on A4 paper with heading and using 'N.P.' and 'run on'

$11-12$

13

4

signs

Manuscript exercise on A4 paper with heading and using $\mathcal{M}$ and 'stet' signs

Manuscript exercise on A4 paper with heading and using 'caps', 'I.c.' and 'u.c.' 15

6

signs

Manuscript exercises on A4 paper with headings and using 'trs' and \# signs

$16-17$

$18-19$

Amended typescript exercises on A4 paper with headings and using $h$ and $C$ signs

Manuscript and amended typescript exercises on A4 paper with headings

$20-21$

and using signs for inserting punctuation marks, 'balloons', margina

instructions, abbreviations and requiring re-arrangement of material

3. MEMOS

Typed and displayed examples to be copied

Graded exercises needing different numbers of carbon copies

Past examination questions

$22-28$

15

$29-30$

4. LETTERS

Short, typed and displayed letters on A5 paper to be copied

$31-36$

20

Short, simple manuscript letters to be typed on A5 paper

Short manuscript letters (with headings and correction signs) to be typed on

$37-48$

$49-59$

27

A5 paper

Short manuscript letters to be typed on A5 paper and needing carbon copy

$60-69$

33

and envelope

Typed and displayed letters on A4 paper to be copied

A4 letters with headings and correction signs and needing carbon copy and envelope

Exercises requiring the composition of letters

$70-81$

37

$82-93$

52

$94-103$

65

5. COMBINATION SIGNS AND PUNCTUATION

Exercises giving practice in the use of combination signs and punctuation

$104-106$

67

6. ROMAN NUMERALS

Exercises giving practice in the use of roman numerals

$107-111$

69

7. TABULATION

Short, easy, typed tabulation exercises without rulings or headings

$112-115$

71

Short, graded, typed tabulation exercises with headings

$116-118$

72

Graded, typed tabulation exercises with rulings

$119-123 \quad 73$

Graded, typed tabulation exercises with headings and rulings

$124-131$

75 
Graded tabulation exercises in manuscript which do not need corrections or re-arrangement

Manuscript tabulation exercises up to examination standards and needing corrections and re-arrangement

\section{FORMS AND DOCUMENTS}

Exercises requiring forms or documents to be designed or copied and

9. DISPLAY

Various exercises including postcards and labels, statement of account, programme, menu, agendas, itinerary, pricelists, invoices and general display material. The exercises also require the typist to make changes, re-arrange material and generally obey instructions given

10. SPEED TESTS

Tests containing 250 to 500 standard words with stroke counts at the end of

$187-190$ 